\title{
Public Health Economics Citizen Expectations, Rights and Responsibilities in the Digital Age
}

\section{Wortley D*}

Vice President of the International Society of Digital Medicine (ISDM), UK

*Corresponding author: David Wortley, Vice President of the International Society of Digital Medicine (ISDM), GAETSS, UK, Tel: +441327811827; Email: david@360in360ix.co.uk

\section{Editorial}

Volume 2 Issue 1

Received Date: February 11, 2019

Published Date: February 25, 2019

DOI: $10.23880 /$ jqhe- 16000112

\section{Abstract}

Digital Technologies are creating an unprecedented and disruptive challenge to all aspects of society. Whilst it can be argued that these technologies, like all previous advances in human communications and knowledge, have led to significant improvements in the overall quality of life, these benefits have to be balanced against the potential costs and risks brought about by these developments.

This article is a personal opinion/commentary about the impact of digital technologies on public health and the future relationship between citizens and health professionals necessary for a sustainable public health service.

\section{Introduction and Background}

Advances in communications technologies throughout human history have had a direct impact on Public Health and the Economics of public health provision. On the negative side, the accessibility and affordability of transportation has contributed to the transfer of communicable diseases throughout populations. In modern times, mass transportation of people has contributed to the phenomenon of pandemics which, in some cases, has resulted in the deaths of many thousands of people and placed massive strains on healthcare systems.

On the positive side, these same technologies have acted as a catalyst to commerce and trade, generating wealth which, through taxation, has supported the evolution of publicly-funded health provision. Additionally, the greater mobility of people has also arguably led to changes in breeding patterns and subsequent health benefits from genetic diversity.
Today's digital communications technologies have also helped to enable quantum changes in our understanding of health factors, our ability to diagnose and treat medical conditions and, through big data analytics and artificial intelligence, our capability to plan for the future.

This complex combination of factors has seen an age of exponential change in the late 20th and early 21st century, during which time we have seen significant increases in life expectancy and shift in causes of mortality from communicable diseases to lifestyle related conditions.

The final factor in the equation has been the impact on birth rates which, coupled with greater longevity, has seen a steady fall in the proportion of the general population who are in employment and thus able to make a financial contribution to public health systems.

\section{Citizen Expectations}

In the UK, The National Health Service Act of 1946 came into force in July 1948, with the following provision: 


\section{Journal of Quality in Health Care \& Economics}

"The Act provided for the establishment of a comprehensive health service for England and Wales. There was separate legislation produced for Scotland and Northern Ireland. The first Minister of Health was Aneurin Bevan MP. The Act stated that it shall be the duty of the Minister of Health to promote the establishment of a health service to secure improvement in the physical and mental health of the people and the prevention, diagnosis and treatment of illness. The Act stated that the services shall be free of charge. The Act brought together a wide range of medical services under one organization, including hospitals, doctors, nurses, pharmacists, opticians and dentists. Local voluntary hospitals were brought into national public ownership and were organized by regional hospital boards, family doctors became self-employed and local authorities held responsibility for community services such as immunizations, maternity clinics and community nurses."

It was this Act that was largely responsible for the concept of public health services being "Free at the point of delivery". The economics of this Act were based on the "National Insurance" tax contributions made jointly by both employers and employees.

The National Health Service has undoubtedly made a fantastic contribution to public health. In my own case, my father's quadruple heart bypass operation transformed his life and my mother's publicly funded health care in her later years struggling with dementia was invaluable to both of us.

The consequence of the National Health Service and other publicly funded health services is that citizens have an expectation of free health care at the point of delivery with additional choices based on payment for private health care.

Critically, these expectations take no account of personal responsibility for one's own health. "In essence, publicly funded health care is seen as a right without any corresponding responsibilities."

\section{Private Health Insurance}

Private Health Insurance and associated legislation to protect people with pre-existing conditions also generally operates on a similar principle to the National Health Service in that it traditionally has taken no account of personal life styles (with the exception of questionnaires about risks associated with smoking and/or alcohol).

\section{Impact of Disruptive Digital Technologies}

The economic model upon which both National Health Services and Private Health Insurance has been based is, in my opinion, seriously flawed because of the demographic changes that have taken place and are increasingly relevant as the causes of mortality shift from communicable diseases (which tend to be random in nature) and lifestyle related conditions (which we have some control over).

We are already beginning to see some changes within the private health insurance sector enabled by developments in digital technologies which have a direct influence on both life style behaviours and the costs of health care. In particular, health insurance providers are offering discounts and special terms for users of wearable devices that track physical activity.

\section{Conclusions}

In my opinion, the challenges created by these exponential changes to society, make current public health care economically unsustainable in its current form because of the ageing society phenomenon and the lack of a causal connection between citizen rights and responsibilities.

Digital technologies which monitor lifestyle behaviours influence those behaviours and increasingly have the potential to compensate for both lifestyle behaviours and existing conditions such as diabetes will become important to the economics of public and private health care.

Looking further to the future with likely developments in artificial intelligence, internet of things and nanotechnologies, we could well see the emergence of hybrid humans with embedded technologies that both monitor and mange personal health, all seamlessly linked to health care providers in a system which better connects citizen rights to responsibilities.

\section{Disclaimer}

This article is solely the personal opinion of the author and does not represent the views, opinions or policies of any other individual or organization.

\section{About the Author}

David Wortley is a Vice President of the International Society of Digital Medicine (ISDM) and the Founding 


\section{Journal of Quality in Health Care \& Economics}

President of the European Chapter of ISDM. He is a recognized global authority on the practical application of emerging and enabling technologies in areas such as health, environment, business development and education.

Wortley D. Public Health Economics Citizen Expectations, Rights and 